\title{
Docosahexaenoic Acid (DHA), an Important Fatty Acid in Aging and the Protection of Neurodegenerative Diseases
}

\author{
Rodrigo Valenzuela ${ }^{1, *}$, Julio Sanhueza² and Alfonso Valenzuela ${ }^{2}$ \\ ${ }^{1}$ Nutrition and Dietetic School, Faculty of Medicine, University of Chile, Santiago, Chile \\ ${ }^{2}$ Lipid Center, Institute of Nutrition and Food Technology (INTA), University of Chile, and Faculty of Medicine, \\ University of Los Andes, Santiago, Chile
}

\begin{abstract}
Docosahexaenoic acid (DHA) is a fatty acid essential for the proper development and functioning of the nervous and visual system. DHA is found in significant concentrations in the phospholipids of neuronal membranes. DHA is provided by the mother during the fetal and early infancy life, during pregnancy and through breastfeeding. Given the importance of an adequate supply of the fatty acid to the newborn, it has been suggested DHA supplementation to the mother before and during the pregnancy and also during the breastfeeding period. In the recent years, research from different scientist have established that DHA has an important role in the development of the nervous system, as well as having an important key role in the preservation of this tissue, especially during aging and in some neurodegenerative diseases, such as Alzheimer's disease, Multiple Sclerosis and Parkinson's disease. DHA may preserve the integrity and the neuronal viability against different metabolic insults and/or cytotoxic events, among which inflammation and oxidative stress are the most relevant. The neuroprotective effects of DHA in neural tissue are mediated by a metabolic derivative, known as neuroprotectin D-1. This molecule may respond to aggression having anti-inflammatory, antiapoptotic and even neuroregenerative effects, which may contribute to preserve the proper neuronal viability as well as the health and function of the nervous system. This review discusses different evidences about the neuroprotective effect of DHA, during aging and against some neurodegenerative diseases, highlighting the important role of the proper nutrition in this protection.
\end{abstract}

Keywords: Docosahexaenoic acid, neurodegenerative diseases, brain aging, neuroprotection, neuroprotectin D-1, nutrition and disease prevention.

\section{INTRODUCCTION}

The scientific and technological development observed since the late nineteenth century until nowadays has caused a significant increase in the life expectancy of the population, being people over 65 a significant and yearly increasing $15 \%$ of the population [1]. As result, the increase in the life expectancy has also increased the prevalence of diseases associated to aging, especially some neurodegenerative diseases such as Alzheimer's disease, Multiple Sclerosis and Parkinson's disease [2]. These illness, besides its increasing with age, are also associated to the socioeconomic status, work and physical activity, family history and genetic, and during the last two decades, the nutrition has also aroused as a relevant factor [3]. In this sense, there is general consensus that a healthy diet may help to prevent the development of many diseases such as obesity, hypertension, diabetes mellitus, stroke, certain kinds of cancers and now some neurodegenerative diseases [4]. Epidemiological evidences suggest that populations having a significant consumption of fish, a food rich in $n-3$ long-chain polyunsaturated fatty acids ( $\mathrm{n}-3$ LCPUFA), show lower

*Address corresponding to this author at the Nutrition and Dietetic School, Faculty of Medicine, University of Chile, Box 1027. Independencia, Santiago, Chile; Tel: 56-2-9786014; Fax: 56-2-9786182;

E-mail: rvalenzuelab@med.uchile.cl incidence of neurodegenerative diseases [5]. $n-3$ LCPUFA, especially docosahexaenoic acid (DHA, C22: $6 \Delta 4,7,10,13,16,19 ; n-3)$, play a fundamental role in the development and preservation of the nervous system, and in recent years solid evidences for their involvement in the prevention and/or eventually in the treatment of neurodegenerative diseases have appeared [6]. DHA is found in high concentrations in the nervous system, especially in the phospholipids of neuronal and glial membranes (plasmatic and synaptosomal membranes). However, as aging progress and during the development of some neurodegenerative diseases, a significant reduction in the DHA content of the brain is frequently produced [5], especially in the cortex, cerebellum and hypothalamus, which result in a considerable reduction in the fluidity of neuronal membranes and in alteration of the neuronal homeostasis [7, 8]. Beyond the fluidizing effects of DHA at the neuronal membranes, the fatty acid also exerts other protective effects, which are mediated by a recently metabolic derivative identified as neuroprotectin D-1 (NPD-1). This molecule may protect neurons against oxidative stress, inflammation, the disruption of the cytoskeleton, and from the activation of apoptotic signaling pathways [9, 10]. NPD-1, formed from DHA, is normally present in the nervous system, especially in the brain, but its formation is especially relevant in states and/or situations that may 
compromise the activity, integrity and neuronal viability, as it is the case of neurodegenerative diseases, brain injury by ischemia - reperfusion, leukocyte infiltration and after the activation of proapoptotic signaling pathways $[9,11,12]$. In this context, NPD-1 has antiinflammatory, antiapoptotic and even neuroregenerative effects, which would help to preserve both, the neuronal functioning and the nervous system structure [13]. A significant reduction of the neuronal DHA content is produced during the developing of neurodegenerative diseases. This reduction, which is produced not only by dietary factors, (i.e. low intake), it is also produced by some metabolic process, such as increased metabolic DHA utilization and/or oxidation [5]. The greatest evidence about the neuroprotective effect of DHA has been observed in Alzheimer's disease. DHA may suppress the cytotoxic effects derived from the accumulation of the $\beta$-amyloid peptide, being this suppressing effect the main mechanism associated to the neuroprotective action of the fatty acid $[9,13]$. Facing this evidence, it is reasonable to consider as beneficial the increase in the consumption of DHA by eating foods rich in the fatty acid, such as fatty fish or DHA containing supplements. This work reviews the neuroprotective effects of DHA in the context of the brain aging and some neurodegenerative diseases. It is also suggested to promote the consumption of foods and/or supplements rich in DHA, as an effective strategy for preserving the brain function during aging and especially to prevent the incidence, or to delay the onset of neurodegenerative diseases.

\section{DHA AND BRAIN PHYSIOLOGY}

DHA is a LCPUFA with six double bonds, which belong to the series or family of $n-3$ polyunsaturated fatty acids. It is relevant that DHA is the most unsaturated fatty acid found in our organism and is specifically concentrated in the brain, retina and sperms of higher animals [14, 15]. DHA, when provided by the diet, comes mainly from marine organisms such as fish (fatty or blue species), shellfish, and algae [16]. The first report of a deficiency of n-3 fatty acids was documented in 1982, which described the case of a six year-old girl, who after intestinal surgery received for five months parenteral nutrition without the addition of n-3 fatty acids [17]. After the nutritional intervention, the girl presented dermatitis associated with neurological symptoms including neuropathy, blurred vision and psychological disturbances, and accompanied by very low plasma DHA levels, which suggested an important role of n-3 LCPUFA, especially DHA, in the functions of the nervous system. In fact, it is now widely accepted that DHA is the most important $n-3$ LCPUFA in the formation of neuronal plasma and synaptosomal membranes (synaptic vesicles), especially in the brain $[18,19]$. DHA approximately amounts $30-40 \%$ of the fatty acid content of phospholipids forming the gray matter of the cerebral cortex and retinal photoreceptors [20]. The most important growing of the brain in humans occurs during the third trimester of fetal development and in the first two years of life [19]. It is during these periods that the requirements of $n-3$ and n-6 LCPUFA are considerably increased, especially the requirements of DHA and arachidonic acid (AA, C20: 4 $\Delta 5,8,11,14 ; n-6)$ [21]. Animal studies have shown that the reduced availability of DHA during the perinatal period is associated with alterations in the establishing of neuronal networks, and also with multiple expressions of synaptic pathologies, including deficits in serotonin neurotransmission and alterations in the mesocorticolimbic dopamine pathway, neurocognitive deficits, and a greater anxious behavior, aggression, depression and decreased visual acuity [18]. Similar problems have been observed in preterm primates and humans, which can be reversed dramatically after $n-3$ LCPUFA supplementation. DHA intake remains even essential after the end of the brain development. It is required to maintain the normal brain functions, including synaptic plasticity, neurotransmission and visual function [22].

\section{DHA AND BRAIN METABOLISM}

Due to the lack of enzymes necessary to carry-out the neuronal de novo DHA and AA synthesis, these fatty acids must be obtained either directly preformed from the diet, or be synthesized from their respective precursors; $\alpha$-linolenic acid (ALN, C18: $3 \Delta 9,12,15$; n3) for DHA, and linoleic acid (LA, C18: $2 \Delta 9,12, \mathrm{n}-6)$ for AA [23]. This synthesis occurs mainly in the liver and to a lesser extent in the astrocytes of the cerebral endothelium, which may export these fatty acids to the neurons [24, 25]. Although is still under discussion how these fatty acids (ALN, LA) can cross the blood-brain barrier, it has been demonstrated that they may diffuse through the phospholipids of neuronal membranes [22]. Other evidences suggest that some membrane proteins may facilitate the transport of ALN and/or DHA through the hematoencephalic barrier. One of these protein transporters has been identified as a caveolin binding protein type or CD36 [23, 24]. However, plasma LCPUFA levels are poorly correlated with the dietary intake of the respective precursors [25]. In fact, in healthy individuals, $\Delta 5$-and $\Delta 6$-desaturases, the key 
enzymes in the conversion process of $L A$ to $A A$ and ALN to DHA, are induced only in the absence of the precursors (LA and ALN) and suppressed when the intake of the respective precursors is sufficient [25]. In contrast, $\Delta 6$-desaturase activity appears to decrease with age, as has been demonstrated in rodent models $[26,27]$. The reduction of the activity of this enzyme could be significantly important during aging, considering that the elderly shows low tissue levels of DHA, especially when the intake of ALN is chronically low [28, 29]. This situation could lead to profound alterations in the metabolism of the nervous system, especially in the density of the synaptosomal vesicles and/or in the release of neurotransmitters, as has been suggested from studies carried-out in the nematode Caenorhabditis elegans deficient for the enzyme $\Delta 6$ desaturase [24]. DHA is present in the phospholipids of neuronal membranes predominantly at the sn-2 position; therefore the incorporation of DHA in membrane phospholipids depends on the cycle deacylation - reacylation, which occurs at the sn-2 position [30]. In rodent brains, this cycle has significant activity [31] and is directly dependent on the specific activity of enzyme phospholipase A2 (PLA2) and of enzymes forming the acyl-CoA synthetase (ACS) system. ACS system performs the activation process by binding the fatty acid to CoA, which is an ATPdependent reaction. Once activated, the fatty acids can be incorporated into phospholipids. ACS isoenzymes 3 , 4 and 6 , are specific for LCPUFA, and in the brain ACS isoform 6 is specific for DHA acylation [32]. At present, there is not sufficient background about the type of phospholipase that participate in the release of DHA from membrane phospholipids. However, it has been established that in astrocytes the release of DHA is a calcium-dependent mechanism and non-depending of PLA2 [33]. The role of PLA2 in neurons has not been clearly demonstrated. However a study in rat hippocampus suggest that the enzyme is of fundamental importance in the release of DHA in neuronal tissue [29]. Figure 1 shows a hypothetical proposal of how DHA may be incorporated into the phospholipids of neuronal membranes.

\section{DHA AND BRAIN AGING}

The presence of high concentrations of DHA, especially in the phospholipids of neuronal and synaptic membranes, has encouraged for more than 30 years the research about the roles of DHA in the nervous system. The evidence has demonstrated that during the embryonic and fetal stages and during the first years of life, DHA plays a key role in the growth and development of the nervous and visual systems, actively participating in the processes of neurogenesis, neuronal migration, myelination and synaptogenesis $[14,15]$. Brain DHA accretion, which occurs during fetal life and the two first extra uterine years, can directly impact on cognitive development, visual, auditory, and in the memory and learning capabilities of children [18]. As result of these observations, it is now strongly recommended to increase the consumption DHA

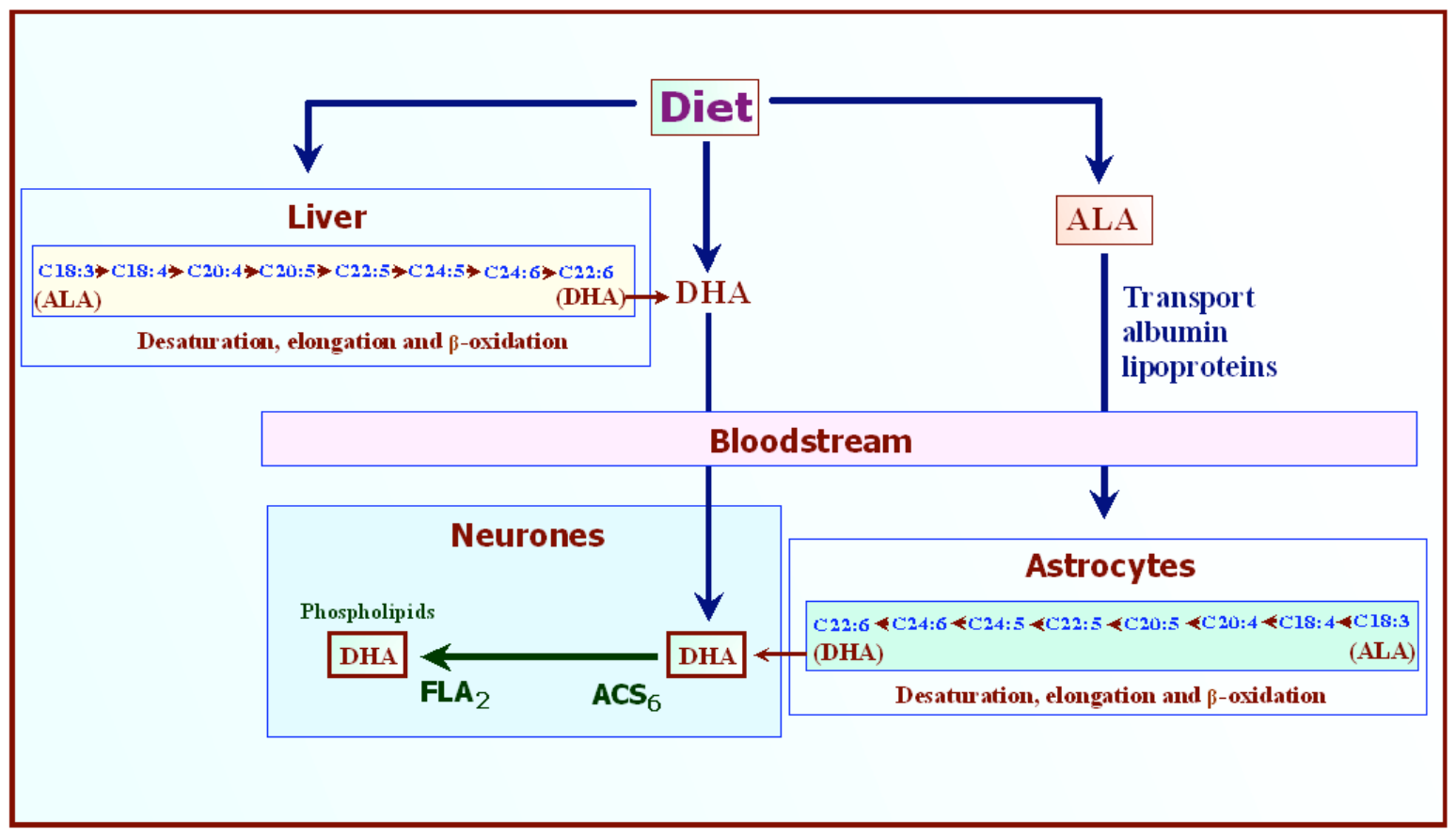

Figure 1: Incorporation of DHA into the phospholipids of neuronal membranes. 
during the pregnancy and childhood, in order to ensure the proper development of the nervous and visual systems [14]. The close relationship between DHA and the developing of the nervous system has encouraged investigators to study what happens with this fatty acid during aging. It has been observed that as the individual ages, the content of DHA in neural tissue is significantly reduced, being even greater this decrease in those individuals that has developed neurodegenerative diseases [7]. This significant DHA reduction may be consequence of either; a lower intake of the fatty acid or of its metabolic precursor and/or to an increased DHA utilization at the cellular level [34]. DHA plays a relevant role in the preservation of both the histology and physiology of the neuronal tissue as the individual ages, and also by preserving the nervous system functions among which memory and learning are the most remarkable [35]. Several epidemiological studies have strongly established that a higher intake of foods rich in DHA ("blue" or fatty fish and/or nutritional supplements based on fish or microalgae oils) is highly correlated with a lower risk of developing neurodegenerative diseases [8, 28]. These observations are also associated with clinical history, which indicates that patients with neurodegenerative diseases have significantly lower plasma and brain DHA levels [5, 7].

\section{NEUROPROTECTIN D-1 AND NEUROPRO- TECTION}

A relevant question about the attributed neuroprotective effects of DHA in aging and especially against neurodegenerative diseases is referred as how the fatty acid may exerts these effects at the molecular level. Their role in the fluidity of neuronal membrane appears as one of the most relevant attributes [36]. In fact, up to day the classification of the membrane fluidity is based on the level of DHA present in the phospholipids that form the membrane matrix [37]. However, the higher fluidity that DHA confers to neuronal membranes is not sufficient to explain the neuroprotective effects attributed to the fatty acid. As result of multiple investigations, it has been established that acylation of DHA at the sn-2 position in membrane phospholipids and its liberation by the activity of PLA2, are additional features of DHA, by itself, to achieve an additional neuroprotective action against certain cytotoxic situations, as are neurodegenerative diseases $[37,38]$. It is not casual the almost exclusive presence of DHA at the sn-2 position in the phospholipids of neuronal membranes $(48 \%$ in phosphatidylcholine, $52 \%$ in phosphatidylserine and $20 \%$ in phosphatidylethanolamine) [39]. It was the discovery of a number of bioactive compounds derived from DHA, called protectins and resolvins, which show cytoprotective properties, that has open the way to a better understanding of how DHA may exert at the molecular level its neuroprotective actions [10, 40]. Among these bioactive DHA-derivatives, NPD-1 (protectin D1 or D1 neuroprotectin: 10R, 17Sdihydroxy-docosa-4Z, 7Z, 11E, 13E, 15Z, 19Zhexaenoic acid) appears as the most relevant neuroprotective agent [30]. NPD-1 is generated once DHA is released from the membrane phospholipids by the hydrolytic action of PLA2, followed by the action of the enzyme 15-lipoxygenase which initiates a complex process of lipooxidation, epoxidation and hydrolysis, resulting in the formation of NPD-1 [41]. Figure 2 shows a diagram of the formation of NPD-1. NPD-1 may exert its neuroprotective function either; through a postulated receptor (as yet unidentified), which may act in an autocrine form; and/or NPD-1, once formed, may be diffused to other neurons. The mechanisms involved in the neuroprotection afforded by NPD-1 may include: (i) inhibition of the expression of proinflammatory cytokines (TNFa and IL1 $\beta$ ); (ii) inhibition of the generation and of the neurotoxicity of $\beta$-amyloid peptides and Ab42; (iii) increased gene expression of antiapoptotic molecules (Bcl-2 and $\mathrm{Bcl}-\mathrm{xL}$ ); (iv) reduction in the gene expression of proapoptotic molecules (Bax and Bad) and; (v) increased neuronal antioxidant potential [42]. Moreover, inflammatory cytokines and oxidative stress may activate the synthesis of NPD-1 [43].

\section{DHA AND NEURODEGENERATIVE DISEASES}

A wide range of epidemiological, clinical and basicexperimental studies have currently demonstrated the beneficial effects of $n-3$ LCPUFA consumption in the prevention and/or treatment of many diseases [44], among which are: cardiovascular disease [45-47], obesity and diabetes [48], some cancers [49-51], inflammatory diseases such as rheumatoid arthritis [52, 53], inflammatory bowel disease [54, 55] and asthma $[56,57]$, non alcoholic fatty liver disease and steatohepatitis [58-60] chronic kidney failure [61], and injury caused to the heart and liver after ischemia/reperfusion episodes [62-64] and specificaly to the brain level, neurological disorders such as schizophrenia [65], depression [66], migraine [67] and neurodegenerative diseases such as Alzheimer's disease [68], Multiple Sclerosis [69] and Parkinson's disease [70]. The evidence of the beneficial effect of $n$ 3 LCPUFA, specifically of DHA, and of its derivate 


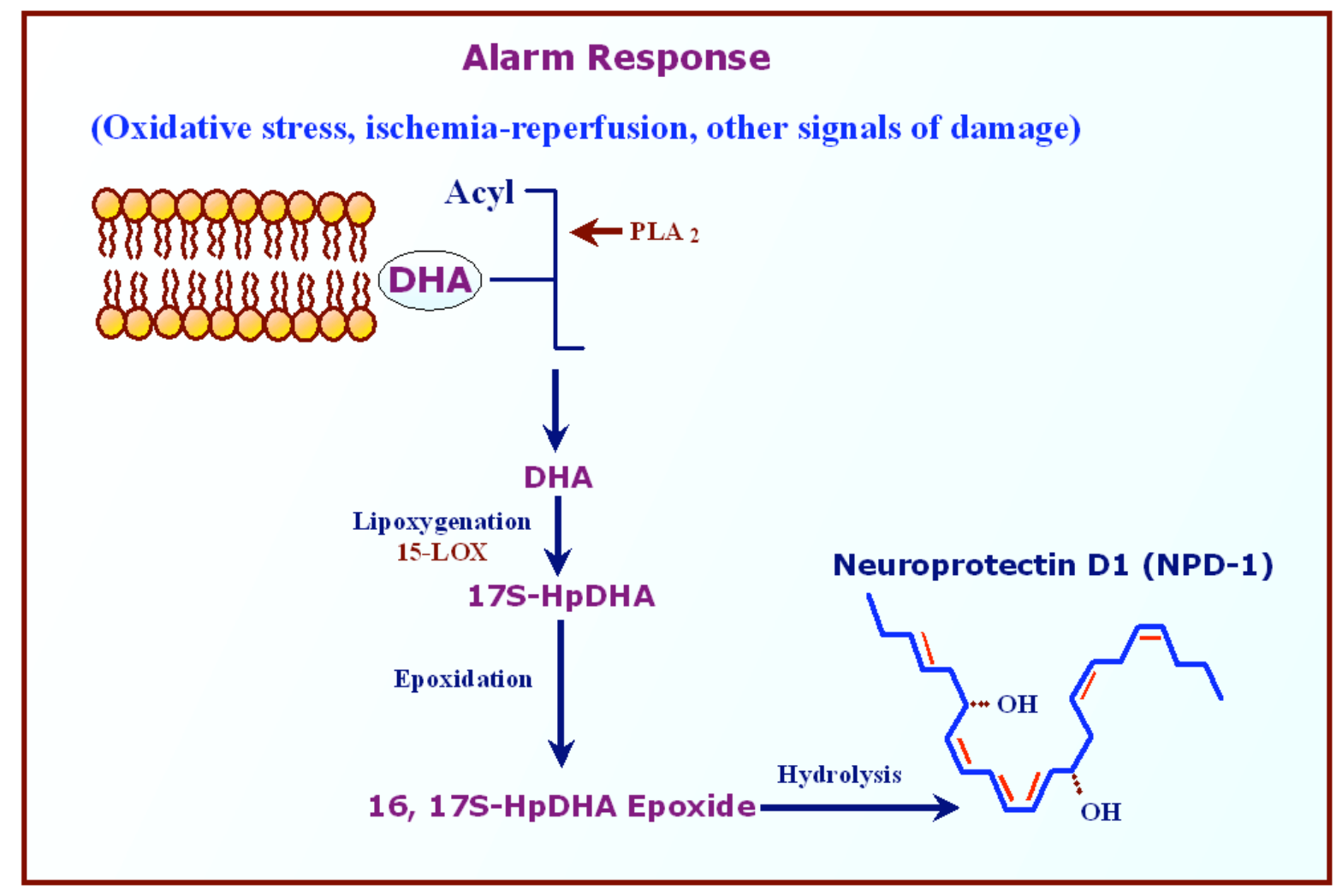

Figure 2: Biosynthesis of Neuroprotectin D-1 (NPD-1).

NPD-1, has been clearly demonstrated mainly in neurodegenerative diseases $[12,71]$.

\subsection{DHA and Alzheimer's disease}

Alzheimer's disease (AD) is a progressive dementia, which is early manifested by the loss of synaptic function and memory capacity of the individual. The number of patients who are diagnosed the neuropathological disorder has increased substantially in all countries, mainly in those populations where has been produced an increase in the life expectancy. In fact, it is estimated that about $5 \%$ of the population that borders 65 years, is affected by AD. The prevalence of the disease doubles every 5 years over 65 years [72], and many studies suggest that almost half the population up to 85 years show symptoms related to the disease [73, 74]. The presence of the $\beta$-amyloid peptide, which is associated with neurotoxic effects, is one of the characteristic expressions of the molecular damage observed in the patients of $A D[75,76]$. Its origin occurs from the degradation (altered or incomplete) of the $\beta$-amyloid peptide precursor (APP) [77]. A significant reduction in DHA levels, both in erythrocytes and in the brain, is observed in AD, specifically in the frontal lobe, and occipital and temporal cortex [78]. It is also produced a replacement of DHA by saturated fatty acids (SFA) in neural phospholipids, among which myristic acid (14:0), palmitic (16:0) and stearic acid (18:0) are the most frequent replacing fatty acids [79]. Thus, it is likely that changes in the ratio AGS/n-3 and $n-6 / n-3$ LCPUFA could alter the neuronal function, especially at the membrane phospholipids, which in turn could result in neurological deficits. The altered fatty acid composition observed in the brains of AD patients could be caused by a deficiency in the LCPUFA transport from the blood to the brain [71]. It is remarkable that in patients with certain types of dementia or cognitive impairment it is observed the same reduction in the levels of $n-3$ LCPUFA, especially DHA $[80,81]$. It is also remarkable that a decrease of DHA in plasma does not appear to be unique to $A D$ patients; it is also common in the general cognitive impairment observed during physiological aging [82]. Many studies have demonstrated that a high intake of DHA is associated with a lower risk of $A D$, and in individuals diagnosed the disease, consumption of DHA result in a decrease in the progression of the characteristic symptoms, especially in relation to the cognitive impairment $[71$, 83].

\subsection{DHA and Multiple Sclerosis}

In the case of multiple sclerosis (MS), the benefits associated with n-3 LCPUFA, especially DHA, have 
been shown in both the mental and the physical expression of the disability. Evaluation of patients that has been supplemented with DHA indicates a significant improvement in the symptoms characteristic of the disease [74, 84]. Some of these beneficial effects have been observed even in patients who consume a diet low in fat, but supplemented with n-3 LCPUFA of marine origin (fish oil). However, the evidence regarding a benefits in the progression of MS is not yet fully conclusive [85]. Considering the information currently available, it is not yet possible to establish a direct association between the consumption of $n-3$ LCPUFA and a lower incidence of MS. More studies are required on this issue $[85,86]$. A study showed a relationship between reduced risk of this disease and the consumption of fish, but only among women [87]. Currently, most hypotheses about MS suggest that $n-3$ LCPUFA would provide the molecules needed to rebuild the myelin sheath, which is severely affected in patients with this pathology [86, 87]. Dietary supplementation with n-3 LCPUFA helps to reduce the severity of MS in patients recently diagnosed the pathology and may delay the onset of symptoms. This is especially effective when supplementation is from marine oils along with vitamins and dietary professional counseling [88]. Perhaps, the severity of MS disease can be reduced in some cases by modulating the immune response. Several studies have shown that a reduction in the dietary fat intake and changes in the ratio $n-6 / n-3$ produce positive changes in the immune response [89]. The consumption of nutritional supplements rich in n-3 LCPUFA has been associated with a reduced activity and plasma levels of circulating pro inflammatory immune cells (lymphocytes, polymorph nuclear neutrophils and monocytes), including the reduction in the production of inflammatory mediators [86, 87, 90]. These records allow to suggest a protective role of $n-3$ LCPUFA in MS, which would lead to establish the potential of the use of n-3 LCPUFA as anti-inflammatory and neuroprotective agents in the disease, although it remains a topic for further research.

\subsection{DHA and Parkinson's disease}

In contrast to $A D$, data about a relationship between fat intake and the risk of developing Parkinson's disease (PD) is very limited. Two studies have only established an association between high consumption of saturated fatty acids, low intake of n-3 LCPUFA and the increased of the risk to develop PD [91, 92]. To date researchers have not been able to establish a direct association between low intake of n-3 LCPUFA and increased risk of development of PD. However, as in patients with $A D$, in the brains of people with $P D$ it is also observed a significant decrease in the levels of $n-3$ LCPUFA, especially DHA [93]. Research in primates allow to observe a significant reduction in the extent of levodopa-induced dyskinesia (a damage model for the PD) in animals supplemented with DHA. Authors suggest that these effects would be mediated by the activation of retinoid $X$ receptors (RXR) [94]. In addition, data from other investigations show a drastic drop in neural DHA levels [95,96]. Also, the dietary supplementation of animals with DHA reduced the neuronal damage produced by a characteristic PDinducer agent, the neurotoxin 1-methyl-4-phenyl1,2,3,6-tetrahydropyridine (MPTP) [97]. Currently, the available information is not sufficient to establish a neuroprotective effect of DHA in the development of $P D$, being necessary to carry out more studies on the subject.

\section{DIETARY SOURCES AND INTAKE OF DHA}

The metabolic precursor of $n-3$ LCPUFA, ALN, is found almost exclusively in land-based plant foods, such as nuts (walnuts 6\%), chia seeds (Salvia hispanica) and flax seeds (Linum usitatissimum) and in some edible oils, such as those obtained from soybean (7\%), canola (11\%), rosa mosqueta (Rosa rubiginosa) (27\%), camelina (Camelina sativa) (38\%), sacha inchi (Plukenetia volubilis) (46\%), perilla (Perilla frutescens) $(58 \%)$ salvia sclarea (Salvia sclarea) $(60 \%)$ and chia $(65 \%)$. While, the already-formed DHA is found

Table 1: Shows the DHA Content of Different Commonly Edible Fish. Date from the United Stated Department of Agriculture (USDA). National Nutrition Database 2010

\begin{tabular}{|c|c|}
\hline Common dietary sources & DHA content $(\mathbf{g} / \mathbf{1 0 0})$ \\
\hline \hline Anchovy & 1.3 \\
\hline Salmon, farmed & 1.1 \\
\hline Salmon, wild & 1.1 \\
\hline Mackerel, Atlantic & 0.7 \\
\hline Bluefish & 0.6 \\
\hline Sardines, Atlantic & 0.5 \\
\hline Trout & 0.7 \\
\hline Golden bass & 0.7 \\
\hline Swordfish & 0.7 \\
\hline Tuna & 0.6 \\
\hline
\end{tabular}


exclusively in marine foods, either of animal or vegetal origin, especially in fatty fish such as tuna, mackerel, menhaden, salmon, and some algae and microalgae $[98,99]$. Unfortunately, the western consumption of ALN and DHA is very low, which has forced the development of nutritional supplements rich in DHA, either from fish oils or microalgae, and also to add this fatty acid to some foods. Table 1 shows the DHA content of different commonly edible fish. In this regard, in addition to the capsules containing fish oil or DHA concentrates, which are very popular and widely available, DHA can be also added to various foods such as milk, dairy products, juices, beverages, bakery products, etc. The fatty acid may be provided in the form of triglycerides, phospholipids, and in pure form as ethyl esters [100]. Today, a wide variety of foods containing DHA are available from the retail and nutraceutical market.

\section{CONCLUSIONS AND PERSPECTIVES}

Neurodegenerative diseases may significantly alter the functioning of the nervous system, reducing the number and altering the function of neurons, and seriously affecting the quality of life of those individuals suffering these diseases. New strategies aiming to the prevention and/or the treatment of neurodegenerative diseases are now of high priority. In this context, DHA and its derivative NPD-1, have emerged as new perspectives for the prevention and/or therapeutic management of these diseases, especially considering the social and economic devastation that neurological diseases may produce to the individual and the family. Future clinical research and nutritional interventions should be planned to establish the necessary doses of DHA needed to achieve significant beneficial effects, as well as to encourage the development and consumption of foods and/or supplements rich in this fatty acid. In this regard, the development of functional foods and/or nutraceutical products containing DHA at different concentrations is an alternative that the pharmaceutical and the food industries should consider very seriously [15]. Today the increase of the consumption of fish or seafoods appear as not entirely feasible, due to the massive depredation of the resource, which has decreased its availability and consequently has increased the price of the products from the sea. Perhaps, in the future the increasing activity of the aquaculture may offer a viable alternative to improve the general consumption of $n-3$ LCPUFA to the western population and helping to prevent the early onset of neurodegenerative diseases.

\section{ACKNOWLEDGEMENT}

The authors are grateful from FONDECYT, FONDEF and INNOVA-Chile the support of their research.

\section{REFERENCES}

[1] Szymański P, Markowicz M, Janik A, Ciesielski M, MikiciukOlasik E. Neuroimaging diagnosis in neurodegenerative diseases. Nucl Med Rev Cent East Eur 2010; 13: 23-31.

[2] Habeck C, Stern Y. Alzheimer's Disease Neuroimaging Initiative. Multivariate data analysis for neuroimaging data: overview and application to Alzheimer's disease. Cell Biochem Biophys 2010; 58: 53-67. http://dx.doi.org/10.1007/s12013-010-9093-0

[3] Stampfer MJ. Cardiovascular disease and Alzheimer's: common links. J Inter Med 2006; 260: 211-23. http://dx.doi.org/10.1111/j.1365-2796.2006.01687.x

[4] Massaro M, Scoditti E, Carluccio MA, Catetina R Nutraceuticals and prevention of atherosclerosis: focus on omega-3 polyunsaturated fatty acids and Mediterranean diet polyphenols. Cardiovasc Ther 2010; 28: 13-9. http://dx.doi.org/10.1111/j.1755-5922.2010.00211.x

[5] Tully AM, Roche HM, Doyle R, et al. Low serum cholesteryl ester-docosahexaenoic acid levels in Alzheimer's disease: a case-control study. Br J Nutr 2003; 89: 483-89. http://dx.doi.org/10.1079/BJN2002804

[6] Ikemoto $A$, Ohishi $M$, Sato $Y$, et al. Reversibility of $n-3$ fatty acid deficiency - induced alterations of learning behavior in the rat: level of $n-6$ fatty acids as another critical factors. J Lipid Res 2001; 42: 1655-63.

[7] Sodeberg M, Edlund C, Kristensson K, G Dallner. Fatty acid composition of brain phospholipids in aging and in Alzheimr's disease. Lipids 1991; 26: 421-25.

[8] Kalminj S, van Boxtel MPJ, Ocke M, Verschuren WM, Kromhout D, Launer LJ. Dietary intake of fatty acid and fish in relation to cognitive performance at middle age. Neurology 2004; 62: 275-80.

http://dx.doi.org/10.1212/01.WNL.0000103860.75218.A5

[9] Bazan NG. Neuroprotectin D1-mediated anti-inflammatory and survival signaling in stroke, retinal degenerations, and Alzheimer's disease. J Lipid Res 2009; 50: 400-5. http://dx.doi.org/10.1194/jlr.R800068-JLR200

[10] Serhan CN, Petasis NA. Resolvins and Protectins in Inflammation Resolution. Chem Rev 2011; 111: 5922-43. http://dx.doi.org/10.1021/cr100396c

[11] Belayev L, Khoutorova L, Atkins KD, Bazan NG. Robust docosahexaenoic acid-mediated neuroprotection in a rat model of transient, focal cerebral ischemia. Stroke 2009; 40: 3121-26.

http://dx.doi.org/10.1161/STROKEAHA.109.555979

[12] Zhang W, Li P, Hu X, Zhang F, Chen J, Gao Y. Omega-3 polyunsaturated fatty acids in the brain: metabolism and neuroprotection. Frontier Biosci 2011; 16: 2653-70. http://dx.doi.org/10.2741/3878

[13] Reinoso MA, Mukherjee P, Marcheselli V, Bergsma D, Hesse R, Bazan N. PEDF Promotes Biosynthesis of a Novel Antiinflammatory and Anti-apoptotic Mediator NPD1 in Retinal Pigment Epithelial Cells. Ochsner J 2008; 8: 39-43.

[14] Uauy R, Hoffman DR, Peirano P, Birch DG, Birch EE. Essential fatty acids on visual and brain development. Lipids 2001; 36: 885-95. http://dx.doi.org/10.1007/s11745-001-0798-1

[15] Valenzuela A. Docosahexaenoic acid (DHA), an essential fatty acid for the proper function of neuronal cells: Their role in mood disorders. Grasas Aceites 2009; 60: 203-22.

http://dx.doi.org/10.3989/gya.085208 
[16] Horrocks LA, Farooqui AA. Docosahexaenoic acid in the diet: its importance in maintenance and restoration of neural membrane function. Prostaglandins Leukot Essent Fatty Acids 2004; 70: 361-72.

http://dx.doi.org/10.1016/j.plefa.2003.12.011

[17] Holman RT, Johnson SB, Hatch TF. A case of human linolenic acid deficiency involving neurological abnormalities. Am J Clin Nutr 1982; 35: 617-23.

[18] McNamara RK, Carlson SE. Role of omega-3 fatty acids in brain development and function: potential implications for the pathogenesis and prevention of psychopathology. Prostaglandins Leukot Essent Fatty Acids 2006; 75: 329-49. http://dx.doi.org/10.1016/j.plefa.2006.07.010

[19] Valenzuela A, Nieto S, Sanhueza J, Nuñez MJ, Ferrer C. Tissue accretion and milk content of docosahexaenoic acid in female rats after supplementation with different docosahexaenoic acid sources. Ann Nutr Metab 2005; 49: 325-32.

http://dx.doi.org/10.1159/000087337

[20] Carlson SE. Docosahexaenoic acid and arachidonic acid in infant development. Seminars Neonatol 2002; 6: 437-49. http://dx.doi.org/10.1053/siny.2001.0093

[21] Uauy R, Dangour AD. Fat and fatty acid requirements and recommendations for infants of $0-2$ years and children of 218 years. Ann Nutr Metab 2009; 55: 76-96. http://dx.doi.org/10.1159/000228997

[22] McCann JC, Ames BN. Is docosahexaenoic acid, an n-3 long-chain polyunsaturated fatty acid, required for development of normal brain function? An overview of evidence from cognitive and behavioral tests in humans and animals. Am J Clin Nutr 2005; 82: 281-95.

[23] Williard DE, Harmon SD, Preuss MA, Kaduce TL, Moore SA, Spector AA. Production and release of docosahexaenoic acid by differentiated rat brain astrocytes. World Rev Nutr Diet 2001; 88: 168-72.

http://dx.doi.org/10.1159/000059781

[24] Lesa GM, Palfreyman $M$, Hall $\mathrm{DH}$, et al. Long chain polyunsaturated fatty acids are required for efficient neurotransmission in C. elegans. J Cell Sci 2003; 116: 496575.

http://dx.doi.org/10.1242/jcs.00918

[25] Kalant D, Cianflone K. Regulation of fatty acid transport. Curr Opin Lipidol 2004; 15: 309-14.

http://dx.doi.org/10.1097/00041433-200406000-00011

[26] Hrelia S, Celadon M, Rossi CA, Biagi PL, Bordoni A. $\Delta 6$ Desaturation of linoleic and $\alpha$-linolenic acids in aged rats: a kinetic analysis. Biochem Int 1990; 22: 659-67.

[27] Cho HP, Nakamura MT, Clarke SD. Cloning, expression, and nutritional regulation of the mammalian $\Delta 6$-desaturase. J Biol Chem 1999; 274: 471-77.

http://dx.doi.org/10.1074/jbc.274.1.471

[28] Kalmijn S, Launer LJ, Ott A, Witteman JC, Hofman A, Breteler M. Dietary fat intake and the risk of incident dementia in the Rotterdam Study. Ann Neurol 1997; 42: 77682.

http://dx.doi.org/10.1002/ana.410420514

[29] Strokin M, Chechneva O, Reymann KG, Reiser G. Neuroprotection of rat hippocampal slices exposed to oxygen-glucose deprivation by enrichment with docosahexaenoic acid and by inhibition of hydrolysis of docosahexaenoic acid-containing phospholipids by calcium independent phospholipase A2. Neuroscience 2006; 140: 547-53.

http://dx.doi.org/10.1016/j.neuroscience.2006.02.026

[30] Serhan CN, Chiang N, Van Dyke TE, Resolving inflammation: dual anti-inflammatory and pro-resolution lipid mediators. Nat Rev Immunol 2008; 8: 349-61.

http://dx.doi.org/10.1038/nri2294
[31] Rapoport SI, Chang MC, Spector AA. Delivery and turnover of plasma-derived essential PUFAs in mammalian brain. J Lipid. Res 2001; 42: 678-85.

[32] Marszalek JR, Kitidis C, Dirusso CC, Harvey Lodish. Longchain acyl-CoA synthetase 6 preferentially promotes DHA metabolism. J Biol Chem 2005; 280: 10817-26. http://dx.doi.org/10.1074/jbc.M411750200

[33] Strokin M, Sergeeva M, Reiser G. Docosahexaenoic acid and arachidonic acid release in rat brain astrocytes is mediated by two separate isoforms of phospholipase A2 and is differently regulated by cyclic AMP and $\mathrm{Ca} 2+\mathrm{Br} \mathrm{J}$ Pharmacol 2003; 139: 1014-22. http://dx.doi.org/10.1038/sj.bjp.0705326

[34] Jicha GA, Markesbery WR. Omega-3 fatty acids: potential role in the management of early Alzheimer's disease. Clin Interv Aging 2010; 5: 45-61.

http://dx.doi.org/10.2147/CIA.S5231

[35] Lukiw WJ, Bazan NG. Docosahexaenoic acid and the aging brain. J Nutr 2008; 138: 2510-14.

http://dx.doi.org/10.3945/jn.108.096016

[36] Saiz L, Klein ML. Structural properties of a highly polyunsaturated lipid bilayer from molecular dynamics simulations. Biophys J 2001; 81: 204-16.

http://dx.doi.org/10.1016/S0006-3495(01)75692-5

[37] Stillwell W, Shaikh SR, Zerouga M, Siddiqui R, Wassall SR. Docosahexaenoic acid affects cell multiple by altering lipid rafts. Reprod Nutr Dev 2005; 45: 559-79. http://dx.doi.org/10.1051/rnd:2005046

[38] Brown DA, London E. Structure and function of sphingolipid and cholesterol-rich membrane rafts. J Biol Chem 2000; 275: 17221-24.

http://dx.doi.org/10.1074/jbc.R000005200

[39] Aveldano MI, Bazan NG. Molecular species of phosphatidylcholine, -ethanolamine, -serine, and -inositol in microsomal and photoreceptor membranes of bovine retina. J. Lipid Res 1983; 24: 620-27.

[40] Mukherjee PK, Marcheselli VL, Serhan CN, Bazan G. Neuroprotectin D1: a docosahexaenoic acid-derived docosatriene protects human retinal pigment epithelial cells from oxidative stress. Proc Natl Acad Sci USA 2004; 101: 8491-96.

http://dx.doi.org/10.1073/pnas.0402531101

[41] Serhan CN. Special Issue on Lipoxins and Aspirin-Triggered Lipoxins. Prostaglandins Leukot Essent Fatty Acids 2005; 73: 301-21.

[42] Chen C, Bazan NG. Lipid signaling: Sleep, synaptic plasticity, and neuroprotection. Prostaglandins \& Other Lipid Mediators 2005; 77: 65-76.

http://dx.doi.org/10.1016/j.prostaglandins.2005.07.001

[43] Aksenov MY, Markesbery WR. Changes in thiol content and expression of glutathione redox system genes in the hippocampus and cerebellum in Alzheimer's disease. Neurosci Lett 2001; 302: 141-45.

http://dx.doi.org/10.1016/S0304-3940(01)01636-6

[44] Fetterman JW Jr, Zdanowicz MM. Therapeutic potential of n3 polyunsaturated fatty acids in disease. Am J Health Syst Pharm 2009; 66: 1169-79. http://dx.doi.org/10.2146/ajhp080411

[45] Hamer M, Steptoe A. Influence of specific nutrients on progression of atherosclerosis, vascular function, haemostasis and inflammation in coronary heart disease patients: a systematic review. Br J Nutr 2006; 95: 849-59. http://dx.doi.org/10.1079/BJN20061741

[46] Roth EM, Harris WS. Fish oil for primary and secondary prevention of coronary heart disease. Curr Atheroscler Rep 2010; 12: 66-72.

http://dx.doi.org/10.1007/s11883-009-0079-6 
[47] De Caterina R. N-3 fatty acids in cardiovascular disease. N Engl J Med 2011; 364: 2439-50. http://dx.doi.org/10.1056/NEJMra1008153

[48] Oliver E, McGillicuddy F, Phillips C, Toomey S, Roche HM. The role of inflammation and macrophage accumulation in the development of obesity-induced type 2 diabetes mellitus and the possible therapeutic effects of long-chain n-3 PUFA. Proc Nutr Soc 2010; 69: 232-43. http://dx.doi.org/10.1017/S0029665110000042

[49] Mandal CC, Ghosh-Choudhury T, Yoneda T, Choudhury GG, Ghosh-Choudhury N. Fish oil prevents breast cancer cell metastasis to bone. Biochem Biophys Res Commun 2010; 402: 602-7.

http://dx.doi.org/10.1016/j.bbrc.2010.10.063

[50] Szymanski KM, Wheeler DC, Mucci LA. Fish consumption and prostate cancer risk: a review and meta-analysis. Am J Clin Nutr 2010; 92: 1223-33. http://dx.doi.org/10.3945/ajen.2010.29530

[51] Gillet L, Roger S, Bougnoux P, Le Guennec J, Besson P. Beneficial effects of omega-3 long-chain fatty acids in breast cancer and cardiovascular diseases: voltage-gated sodium channels as a common feature?. Biochimie 2011; 93: 4-6. http://dx.doi.org/10.1016/j.biochi.2010.02.005

[52] Kremer JM, Lawrence DA, Jubiz W, DiGiacomo R, Rynes R, Bartholomew LE, Sherman M. Dietary fish oil and olive oil supplementation in patients with rheumatoid arthritis. Clinical and inmmunologic effects. Arthritis Rheum 1990; 33: 810-20. http://dx.doi.org/10.1002/art.1780330607

[53] Hurst S, Zainal Z, Caterson B, Hughes CE, Harwood JL. Dietary fatty acids and arthritis. Prostaglandins Leukot Essent Fatty Acids 2010; 82: 315-8. http://dx.doi.org/10.1016/j.plefa.2010.02.008

[54] Knoc B, Matthew B, Roy N, McNabb W. Study of the effects dietary polyunsaturated fatty acids: Molecular mechanisms involved in intestinal inflammation. Grasas Aceites 2009; 60: 8-21.

[55] Bassaganya-Riera Y, Hontecillas R. Dietary conjugated linoleic acid and n-3 polyunsaturated fatty acids in inflammatory bowel disease. Curr Opin Clin Nutr Metab Care 2010; 13: 569-73.

http://dx.doi.org/10.1097/MCO.0b013e32833b648e

[56] Yokoyama A, Hamazaki T, Ohshita A, et al. Effects of aerosolized docosahexaenoic acid in mouse model of atopic asthma. Int Arch Allergy Immunol 2000; 123: 327-32. http://dx.doi.org/10.1159/000053645

[57] Fasano E, Serini S, Piccioni E, Innocenti I, Calviello G. Chemoprevention of lung pathologies by dietary $n-3$ polyunsaturated fatty acids. Curr Med Chem 2010; 17: 335876.

http://dx.doi.org/10.2174/092986710793176401

[58] Araya J, Rodrigo R, Videla LA, et al. Increase in long-chain polyunsaturated fatty acid $n 6 / n 3$ ratio in relation to hepatic steatosis in patients with non- alcoholic fatty liver disease. Clin Sci (London) 2004; 106: 635-43.

\section{http://dx.doi.org/10.1042/CS20030326}

[59] Gormaz JG, Rodrigo R, Videla LA, Beems M. Biosynthesis and bioavailability of long-chain polyunsaturated fatty acids in non-alcoholic fatty liver disease. Prog Lipid Res 2010; 49: 407-19.

http://dx.doi.org/10.1016/i.plipres.2010.05.003

[60] Valenzuela R, Videla LA. The importance of the long-chain polyunsaturated fatty acid $n-6 / n-3$ ratio in development of non-alcoholic fatty liver associated with obesity. Food Funct 2011; 3: 644-48. http://dx.doi.org/10.1039/c1fo10133a

[61] Friedman AN. Omega-3 fatty acid supplementation in advanced kidney disease. Semin Dial 2010; 23: 396-400. http://dx.doi.org/10.1111/j.1525-139X.2010.00748.x
[62] Rodrigo R, Cereceda M, Castillo R, et al. Prevention of atrial fibrillation following cardiac surgery: Basis for a novel therapeutic strategy based on non-hypoxic myocardial preconditioning. Pharmacol Therap 2008; 118: 104-27. http://dx.doi.org/10.1016/j.pharmthera.2008.01.005

[63] Zúñiga J, Venegas F, Villarreal $\mathrm{M}$, et al. Protection against in vivo liver ischemia-reperfusion injury by $\mathrm{n}-3$ long-chain polyunsaturated fatty acids in the rat. Free Radic Res 2010; 44: 854-63.

http://dx.doi.org/10.3109/10715762.2010.485995

[64] Mardones M, Valenzuela R, Romanque P, et al. Prevention of liver ischemia reperfusion injury by a combined thyroid hormone and fish oil protocol. J Nutr Biochem 2012; 23: 1113-20. http://dx.doi.org/10.1016/j.jnutbio.2011.06.004

[65] Laugharne JD, Mellor JE, Peet M. Fatty acids and schizophrenia. Lipids 1996; S1: 163-65. http://dx.doi.org/10.1007/BF02637070

[66] Hibbeln JR, Salem Jr N. Dietary polyunsaturated fatty acids and depression: when cholesterol does not satisfy. Am J Clin Nutr 1995: 62: 1-9.

[67] Wagner W, Nootbaar-Wagner U. Prophylactic treatment of migraine with gamma-linolenic and alpha acids. Cephalalgia 1997; 17: 127-30.

http://dx.doi.org/10.1046/j.1468-2982.1997.1702127.x

[68] Morley JE, Banks WA. Lipids and cognition. J Alzheimers Dis 2010; 20: 737-47.

[69] Mehta LR, Dworkin RH, Schwid SR. Polyunsaturated fatty acids and their potential therapeutic role in multiple sclerosis. Nat Clin Pract Neurol 2009; 5: 82-92. http://dx.doi.org/10.1038/ncpneuro1009

[70] Calon F, Cole G. Neuroprotective action of omega-3 polyunsaturated fatty acids against neurodegenerative diseases: evidence from animal studies. Prostaglandins Leukot Essent Fatty Acids 2007; 77: 287-93. http://dx.doi.org/10.1016/j.plefa.2007.10.019

[71] Cunnane SC, Plourde M, Pifferi F, Bégin M, Fear C, Barberger-Gateau P. Fish, docosahexaenoic acid and Alzheimer's disease. Prog Lipid Res 2009; 48: 239-56. http://dx.doi.org/10.1016/j.plipres.2009.04.001

[72] Cummings JL. Alzheimer's disease. N Engl J Med 2004; 351 : 56-67. http://dx.doi.org/10.1056/NEJMra040223

[73] Forsyth E, Ritzline PD. An overview of the etiology, diagnosis, and treatment of Alzheimer disease. Phys Ther 1998; 78: 1325-31.

[74] Nussbaum RL, Ellis CE. Alzheimer's disease and Parkinson's disease. N Engl J Med 2003; 348: 1356-64.

[75] Hardy JA, Higgins GA. Alzheimer's disease: the amyloid cascade hypothesis. Science 1992; 256: 184-185. http://dx.doi.org/10.1126/science.1566067

[76] Yankner BA. Mechanisms of neuronal degeneration in Alzheimer's disease. Neuron 1996; 16: 921-32. http://dx.doi.org/10.1016/S0896-6273(00)80115-4

[77] Selkoe DJ. Alzheimer's disease: a central role for amyloid. J Neuropathol Exp Neurol 1994; 53: 438-47. http://dx.doi.org/10.1097/00005072-199409000-00003

[78] Guan ZZ, Söderberg M, Sindelar P, Edlund C. Content and fatty acid composition of cardiolipin in the brain of patients with Alzheimer's disease. Neurochem Int 1994; 25: 295-300. http://dx.doi.org/10.1016/0197-0186(94)90073-6

[79] Skinner ER, Watt C, Besson JA, Best PV. Differences in the fatty acid composition of the grey and white matter of different regions of the brains of patients with Alzheimer's disease and control subjects. Brain 1993; 116: 717-25. http://dx.doi.org/10.1093/brain/116.3.717 
[80] Kyle DJ, Schaefer E, Patton G, Beiser A. Low serum docosahexaenoic acid is a significant risk factor for Alzheimer's dementia. Lipids 1999; 34: S245. http://dx.doi.org/10.1007/BF02562306

[81] Conquer JA, Tierney MC, Zecevic J, Bettger WJ, Fisher RH. Fatty acid analysis of blood plasma of patients with Alzheimer's disease, other types of dementia, and cognitive impairment. Lipids 2000; 35: 1305-12. http://dx.doi.org/10.1007/s11745-000-0646-3

[82] Catalan J, Moriguchi T, Slotnick B, et al. Cognitive deficits in docosahexaenoic acid-deficient rats. Behav Neurosci 2002; 116: $1022-31$.

http://dx.doi.org/10.1037/0735-7044.116.6.1022

[83] Barberger-Gateau $P$, Letenneur L, Deschamps V, Pérès K, Dartigues JF, Renaud S. Fish, meat, and risk of dementia: cohort study. BMJ 2002; 325: 932-33.

http://dx.doi.org/10.1136/bmj.325.7370.932

[84] Shinto L, Marracci G, Baldauf-Wagner S, et al. Omega-3 fatty acid supplementation decreases matrix metallopro-teinase-9 production in relapsing-remitting multiple sclerosis. Prostaglandins Leukot Essent Fatty Acids 2009; 80: 131-36. http://dx.doi.org/10.1016/j.plefa.2008.12.001

[85] Weinstock-Guttman B, Baier M, Park Y, Feichter J, LeeKwen $P$, Gallagher E. Low fat dietary intervention with omega-3 fatty acid supplementation in $\mathrm{m}$ ultiple sclerosis patients. Prostaglandins Leukot Essent Fatty Acids 2005; 73: 397-404.

http://dx.doi.org/10.1016/j.plefa.2005.05.024

[86] Marcheselli VL, Hong S, Lukiw WJ, et al. Novel multiple of inhibit brain ischemia-reperfusion-mediated leukocyte infiltration and pro-inflammatory gene expression. J Biol Chem 2003; 31: 43807-17.

http://dx.doi.org/10.1074/jbc.M305841200

[87] Nordvik I, Myhr KM, Nyland H, Bjerve KS. Effect of dietary advice and $\mathrm{n}-3$ supplementation in newly diagnosed MS patients. Acta Neurol Scand 2000; 102: 143-49. http://dx.doi.org/10.1034/j.1600-0404.2000.102003143.x

[88] Kelley DS. Modulation of human immune and inflammatory responses by dietary fatty acids. Nutrition $2001 ; 17$ : 669-73. http://dx.doi.org/10.1016/S0899-9007(01)00576-7

[89] Kew S, Banerjee T, Minihane AM, et al. Lack of effect of foods enriched with plant- or marine -derived $n-3$ fatty acids on human immune function. Am J Clin Nutr 2003; 77: 128795.

[90] Serhan CN, Clish CB, Brannon J, Colgan SP, Chiang N, Gronert K. Novel functional sets of lipid-derived mediators with antiinflammatory actions generated from omega-3 fatty acids via cyclooxygenase 2-nonsteroidal antiinflammatory drugs and transcellular processing. J Exp Med 2000; 192: 1197-204.

http://dx.doi.org/10.1084/jem.192.8.1197

[91] Chen H, Zhang SM, Hernan MA, Willett WC, Ascherio A. Dietary intakes of fat and risk of Parkinson's disease. Am J Epidemiol 2003; 157: 1007-14.

http://dx.doi.org/10.1093/aje/kwg073

[92] De Lau LM, Bornebroek M, Witteman JC, Hofman A, Koudstaal PJ, Breteler MMB. Dietary fatty acids and the risk of Parkinson disease: the Rotterdam study. Neurology 2005; 64: 2040-45.

http://dx.doi.org/10.1212/01.WNL.0000166038.67153.9F

[93] Johnson CC, Gorell JM, Rybicki BA, Sanders K, Peterson EL. Adult nutrient intake as a risk factor for Parkinson's disease. Int J Epidemiol 1999; 28: 1102-09. http://dx.doi.org/10.1093/ije/28.6.1102

[94] Samadi P, Gregoire L, Rouillard C, Berdard PJ, Di Paolo T, Levesque D. Docosahexaenoic acid reduces levodopainduced dyskinesias in 1-methyl-4-phenyl-1,2,3,6tetrahydropyridine monkeys. Ann Neurol 2006; 59: 282-88. http://dx.doi.org/10.1002/ana.20738

[95] Breckenridge WC, Morgan IG, Zanetta JP, Vincendon G. Adult rat brain synaptic vesicles. II. Lipid composition. Biochim Biophys Acta 1973; 320: 681-86. http://dx.doi.org/10.1016/0304-4165(73)90148-7

[96] Julien C, Berthiaume L, Hadj-Tahar A, et al. Postmortem brain fatty acid profile of levodopa-treated Parkinson disease patients and parkinsonian monkeys. Neurochem Int 2006; 48: 404-14.

\section{http://dx.doi.org/10.1016/j.neuint.2005.12.002}

[97] Bousquet M, Saint-Pierre M, Julien C, Salem Jr N, Cicchetti $F$, Csalon F. Beneficial effects of dietary omega-3 polyunsaturated fatty acid on toxin-induced neuronal degeneration in an animal model of Parkinson's disease. FASEB J 2008; 22: 1213-25.

http://dx.doi.org/10.1096/fi.07-9677com

[98] Barceló-Coblijn G, Murphy EJ. Alpha-linolenic acid and its conversion to longer chain n-3 fatty acids: benefits for human health and a role in maintaining tissue $\mathrm{n}-3$ fatty acid levels. Prog Lipid Res 2009; 48: 355-74.

http://dx.doi.org/10.1016/j.plipres.2009.07.002

[99] Mozaffarian D, Wu JHY. Omega-3 fatty acid and cardiovascular disease. J Am Coll Cardiol 2011; 58: 2047-67. http://dx.doi.org/10.1016/j.jacc.2011.06.063

[100] Valenzuela A, Sanhueza J, Nieto S. Docosahexaenoic acid (DHA) essentiality and requirements: why and how to provide supplementation Grasas Aceites 2006; 57: 229-37. http://dx.doi.org/10.3989/gya.2006.v57.i2.43

\section{DOI: http://dx.doi.org/10.6000/1929-5634.2012.01.01.6}

(c) 2012 Valenzuela et al.; Licensee Lifescience Global.

This is an open access article licensed under the terms of the Creative Commons Attribution Non-Commercial License (http://creativecommons.org/licenses/by-nc/3.0/) which permits unrestricted, non-commercial use, distribution and reproduction in any medium, provided the work is properly cited. 